\title{
Healthy Sleep Supplies And Equipment, LLC: A Case Study
}

Timothy E. Moffit, Kalamazoo College, USA

Michelle Gigowski, Kalamazoo College, USA

\begin{abstract}
Aaron Pieper was hired about a year ago to run his brother's small medical equipment supply company. Aaron, an MBA with a sketchy employment history, is confronted with a substantial change in Blue Cross Blue Shield (BCBS) insurance reimbursement terms, and he isn't quite sure how to analyze the impact on the business's operations and finances. Moreover, he is not even certain the business should continue to accept BCBS patients. The reader discovers the underlying management complexities of Aaron's decision through a lively staff meeting and is asked to counsel Aaron with regard to determining the financial consequences of the possible courses of action. The richness of this case is attributed to a practical working capital decision and its impact on operating cash flow. This case is intended for undergraduate courses in corporate finance.
\end{abstract}

Keywords: Working Capital Management; Cash Flow Analysis; Insurance Reimbursement; Leadership; Business Case Study

\section{INTRODUCTION}

feel like a new person! Only six months ago, Healthy Sleep Supplies and Equipment (Healthy Sleep)
equipped me with a CPAP (continuous positive airway pressure) system, and I haven't had a bad night's
sleep since. The staff was so helpful. I can actually sleep through the night without worrying that I'll stop breathing! (Marcy Lay, Healthy Sleep Patient)

Healthy Sleep is a durable medical equipment (DME) company that matches patients who suffer from a temporary suspension in breathing during sleep (i.e., apnea) to a prescribed sleep therapy machine and mask system. Patients with snoring and/or apnea issues rely on Healthy Sleep to provide a physician-recommended positive airway pressure (PAP) device and recurring supplies. Through PAP machine therapy, patients are able to maintain sufficient airway pressure, thereby keeping their airways open during sleep and essentially eliminating respiratory distress and apnea events. This results in improved sleep quality, the ability to lead more productive lives, and often a reduction in long-term, adverse cardiac and vascular events.

\section{DILEMMA}

Aaron Pieper, Healthy Sleep Manager, was pacing his comfortable office Friday afternoon worrying about Blue Cross Blue Shield's (BCBS) new PAP machine reimbursement terms that would become effective in just one month. While Aaron was made aware nearly six months ago of the imminent changes in BCBS reimbursement terms, he had only just begun contemplating the implications for the company's operations and finances. Feeling desperate to find traction in his thinking, he brought the issue to the attention of his billing manager, Amelia Marley.

After reviewing the revised reimbursement schedule provided by BCBS, Amelia seemed concerned. Instead of being reimbursed $\$ 1,000$ for a PAP set-up 60 days after the patient was sold the equipment, Healthy Sleep would receive ten monthly installments of $\$ 100$ beginning one month after the patient was set up on the machine. How would Healthy Sleep maintain sufficient cash flow under the revised BCBS reimbursement schedule when the $\$ 500$ cost per machine is due in full only 90 days after being ordered? Amelia was questioning whether it was worth 
Healthy Sleep's time to service BCBS patients if it wouldn't receive full payment for nearly a year following a PAP equipment set-up.

Both Aaron and Amelia agreed that Healthy Sleep's staff should meet Monday to determine the best course of action regarding sleep equipment and supply sales to BCBS patients.

\section{BACKGROUND}

Healthy Sleep Supplies and Equipment, LLC was established three years earlier by Jason Pieper (age 45), the current CEO of Health Services Southwest, PC (HSS), a \$100 million multi-specialty, physician-owned corporation. Healthy Sleep was a sideline opportunity that HSS could not capture because of regulatory limitations. The HSS board of directors encouraged Jason to take on the Healthy Sleep opportunity personally, which he has done with remarkable success. During each of the two years following the inception year of Healthy Sleep operations, Jason, working part time, and his Healthy Sleep staff doubled year-over-year revenues. The most recent year's revenues exceeded \$1.5 million with about one-half of the revenues from equipment sales and one-half from recurring supply sales.

Due to the dynamic nature of health care and recent substantial revisions in health care legislation and regulations, Jason found himself overwhelmed with HSS's strategic management responsibilities. Because he could not find sufficient time to manage Healthy Sleep while directing HSS, he hired his brother, Aaron Pieper (age 43), about a year ago to manage Healthy Sleep's day-to-day operations.

While Jason Pieper is a driven entrepreneur and health care executive whose mantra is "do the right things right," his brother Aaron has been much less motivated and directed. Although Aaron received his MBA from Southern Illinois University (SIU) 15 years ago, he hasn't had much success establishing a meaningful management career, often citing a lack of opportunities with a "good fit."

Jason thought Healthy Sleep would be a great opportunity for Aaron, since he would have the chance to comfortably run a growing business with an established patient base and a capable staff. Jason hired Aaron at $\$ 80,000$ in annual salary plus six-weeks paid vacation, competitive $401 \mathrm{k}$ contributions, and full health and dental insurance benefits.

\section{HEALTHY SLEEP STAFF}

Amelia Marley (age 38) has worked exclusively in health care services since she graduated from high school. She recently divorced her high school sweetheart; they have no children. Although her education is limited to high school, Amelia has gained much practical business knowledge of clinical health services from the various health care positions she has held over the past 20 years. Her expertise is noticeable in reception, scheduling, and billing. Amelia's current responsibilities include billing, collections, and special projects. Her co-workers at Healthy Sleep are quick to point to the special relationship she has with Aaron. They often go to lunch together, and Aaron delegates many of his managerial responsibilities to Amelia.

In addition to Amelia, Aaron relies extensively on Jill Jackson (age 42), Healthy Sleep's respiratory therapist (RT), for clinical and administrative support. Jill was enrolled in River Valley Community College's RT program while Aaron was completing his MBA program at SIU. They occasionally crossed paths during their college years and have more recently served on the same deacon board at the local Methodist church. Aaron is married to Jill's older sister, Karen. While Jill readily accepts clinical oversight responsibilities, she refuses to accept responsibility for administrative and business operations. At the same time, however, she is quick to offer her opinion on most matters, and is visibly upset when she doesn't get her way. She is generally bossy, cavalier, and obstinate. On the positive side, Jill is detail oriented, quite bright, capable, and earns very high marks in patient care.

Jackie Shoup (age 46) is a part-time receptionist who, in addition to managing the front desk, methodically verifies insurance requirements for all new and existing patients. She also schedules patients for clinical staff 
appointments. During the first two years of operations when revenue volume was relatively low, Jackie also prepared supply orders to be mailed to recurring supply patients. Patients adore Jackie; she is genuinely caring and concerned. She will go to extreme measures to ensure the patient's needs are met fully. She is described by her coworkers as "living her faith." She is active in a local evangelical ministry with her husband, Jeff, who is the pastor of their church. But Jackie is quietly stubborn - very, very stubborn. While she nods in complete agreement with management instructions and directions, she will continue to do things her own way.

Wendy Redips (age 30) is a part-time sleep technician. Wendy has a bachelor's degree in chemistry from Southern Illinois University. Given the lack of local jobs for chemistry majors, she took online courses to earn a certificate in sleep therapy. She has worked for several providers and sleep study labs over the past seven years. The quality of her work and her work ethic are consistently evaluated as average; she is often distracted by her passion for and participation in animal rescue efforts. With her husband, Wendy also manages a community organic food plot from which "sharecropper" members contribute 25 percent of the produce grown to local food banks.

Jewel Carson (age 22) works part time preparing supply orders for patients refilling their mask, filter, and tubing supplies. She took over this responsibility from Jackie about two years ago. She works about 20 hours filling 50 to 60 orders per week. Jewel is very efficient at completing the order requests, and she makes very few mistakes even though supply orders are quite tricky due to the scope and combination of parts. Jewel was captain of her high school cheerleading squad and recently earned an associate's degree in business administration at River Valley Community College. She is currently dating Jason Pieper's oldest son, Kevin. Table 1 provides a personnel summary.

Table 1: Healthy Sleep Personnel

\begin{tabular}{|l|c|c|c|c|}
\hline $\begin{array}{c}\text { Healthy Sleep } \\
\text { Employees }\end{array}$ & Job Title & $\begin{array}{c}\text { Hours Worked } \\
\text { Per Week }\end{array}$ & $\begin{array}{c}\text { Annual } \\
\text { Gross Wages }\end{array}$ & Paid Time Off \\
\hline Jason Pieper, MBA & Owner & $<3$ Hours & Company Profits & N/A \\
\hline Aaron Pieper, MBA & Manager & 40 Hours & $\$ 80,000$ & $6 \mathrm{Weeks}$ \\
\hline Amelia Marley & Billing Manager & 40 Hours & $\$ 52,000$ & $5 \mathrm{Weeks}$ \\
\hline Jackie Shoup & Administrative Assistant & 32 Hours & $\$ 28,000$ & $3 \mathrm{Weeks}$ \\
\hline Jill Jackson, RT & Respiratory Therapist & 40 Hours & $\$ 64,000$ & $4 \mathrm{Weeks}$ \\
\hline Jewel Carson & Supply Sales Support & 20 Hours & $\$ 15,000$ & $3 \mathrm{Weeks}$ \\
\hline Wendy Redips, BS & Sleep Technician & 32 Hours & $\$ 38,000$ & $3 \mathrm{Weeks}$ \\
\hline
\end{tabular}

\section{MONDAY'S MEETING}

Monday morning Aaron called a mandatory staff meeting to discuss how Healthy Sleep would proceed regarding BCBS patients and future reimbursement. While Aaron patiently waited for Amelia to begin the meeting, he couldn't help but become irritated with the fact that his administrative assistant, Jackie, arrived to work seven minutes late. Aaron often wasn't around Healthy Sleep at the start of the work day, so he didn't realize this was actually early for Jackie.

Amelia had spent the weekend analyzing BCBS's reimbursement terms and had decided that Healthy Sleep would be unable to fund the PAP machines if it wouldn't be fully reimbursed for the equipment until nearly a year after the purchase date. However, she couldn't completely explain why she thought this was the case. She sat in the corner of the conference room, calculator in hand, attempting to complete her analysis.

Jewel and Wendy sat next to the window in the conference room and were busy chatting about their weekends and the amazing experience Jewel had on her wine tasting tour with Kevin. She visited vineyards along the Wisconsin coast of Lake Michigan Friday night and all day Saturday. Oh what a fantastic weekend trip Jewel experienced, but Aaron couldn't care less about the conversation. He was now becoming impatient because the meeting was on track to begin 15 minutes late, and he had no idea how to move forward with this seemingly important decision. At this point, he decided to begin the meeting himself. 


\section{Aaron}

Good morning, everyone. We have a minor situation here, and I would like to get everyone's feedback on the subject.

\section{Amelia}

A minor situation, Aaron? I'd say this is a pretty big deal. And you just happen to be in luck, because I think I've solved the issue.

\section{Jill}

Oh, I can hardly wait to hear what you've got to say, Amelia.

\section{Amelia}

Well, Aaron, I just don't think it's a great idea to maintain a relationship with our BCBS patients due to the revised reimbursement terms. We just don't have the right staff to meet the BCBS requirements.

\section{Jackie}

Excuse me, Amelia, but how do you think we will stay busy if you are seriously suggesting we drop half of our patient base? Roughly 50\% of our patients subscribe to BCBS insurance. Aaron, please do tell us what's going on here!

\section{Wendy}

Well, Jackie, it seems that what's going on here is that we are going to be having some extra time on our hands as nearly half of our prospective patients are not going to be serviced by Healthy Sleep in the near future.

\section{Jewel}

Aaron, is this true? I'm only part time as it is. If we don't service BCBS patients moving forward, I'm going to have my hours cut by nearly 50\%. I just cannot afford this!

\section{Aaron}

Ladies, let's not jump to conclusions. I was informed that if we would like to maintain our relationship with BCBS, we must accept their updated reimbursement schedule, and my guess is that the slower payments from BCBS will require extra cash from Jason to pay the bills to our suppliers. Currently, and for another month, we get paid for all BCBS PAP set-ups 60 days following the date of the set-up (i.e., when the patient receives the machine). This was never an issue before because we don't have to pay for the actual CPAP set-up until 90 days following the sale. However, beginning in 30 days, we will be paid ten monthly installments of $\$ 100$, beginning 30 days following a PAP set-up which means...

(Amelia interrupts)

\section{Amelia}

This means it will take about a year for us to get paid instead of two months! Aaron, that means there will need to be operational changes around here to pay the bills...

(Gasps escape from Jill, Jackie, Wendy, and Jewel.) 


\section{Jackie}

Well, this is an issue. How will Healthy Sleep afford to sell the machines? What will keep me busy if I don't have all the BCBS insurance policies to verify? I can go back to packaging supply sales if that will help?

\section{Jewel}

Are you kidding me, Jackie? Aaron, I have faithfully served this business for nearly two years. I am, by far, the most efficient and best qualified to prepare supply packages for our refill patients. I could probably improve our insurance verification process, too.

\section{Amelia}

Jackie and Jewel, please have a little faith. Of course, I have a solution for this! You see, we just need to...

(Jill interrupts)

Jill

Aaron, how will we stay busy enough to keep our jobs? We have to keep the BCBS business, even if we lose money doing it. You can't just turn us out into the streets.

\section{Jewel}

Aaron, I just cannot afford this decision. I am a hard worker, I do a great job, and you promised me at least 15 hours per week! Please, tell me this isn't true! I wonder if I qualify for unemployment...

\section{Aaron}

Please, please, lower your voices. No decisions have been made as of yet, and Amelia has spent some time analyzing the new BCBS reimbursement terms. I just don't know if Jason or Healthy Sleep can afford to front the cash for the PAP machines prior to collecting the full reimbursement for the machine nearly a year after we've paid for it. Jason won't like this...

\section{Jill}

Amelia? You have left this decision to Amelia? Why should I be surprised?! Aaron, do you really think we don't realize what's going on here?

(Amelia interrupts)

\section{Amelia}

Don't you all realize how much thought we've put into this! Jill, you are absolutely correct. This is a major decision, and we have spent many hours discussing our options while not distracting the rest of the staff with this decision.

\section{Aaron}

Yes, Jill, we've worked very hard regarding this decision. Amelia, please do tell us what we recommend Healthy Sleep does, moving forward. 


\section{Amelia}

Well, first of all, everyone just needs to relax. Aaron, if my calculations are correct, I'm thinking we need to look to a new patient base because we just can't wait a year to get paid. If we want to stick with BCBS, Jason will need to finance the PAP equipment, and we most certainly will have to cut...

(Jill interrupts)

Jill

If your calculations are correct! Aaron, we can't maintain operations if we don't maintain BCBS patients; I just know it! Plus, I've been networking with a number of my friends from RT school who work in sleep labs around the state, and it seems it's only going to get more and more difficult to collect from insurance companies. And, I hear more companies are thinking about stretching their reimbursement schedules.

Also, how can we turn our backs on BCBS when my friend across town at Sleep Tech says that Jason has the inside track on the state employee union's BCBS health insurance plan? It should raise our BCBS set-ups each month by an additional patient. A year from now we could be doing 12 more BCBS patients per month...that's huge!

We just can't take the chance of losing all of this business. It only costs Healthy Sleep \$500 per CPAP machine, and BCBS is still paying for the PAP set-up; it's just taking a little longer to collect the payment in full!

\section{Wendy}

I just, umm..., well I just think Amelia is right here. It's too risky. I'd rather not waste our time with set-ups that will take a year to collect payment when Amelia can look to other referral sources that will pay more quickly. We need to drop BCBS patients; it's just too long to wait for payment.

\section{Amelia}

I'm glad someone is finally seeing things my way! It's our best option, don't you think, Jackie?

\section{Jackie}

Sure, it sounds like you've done a lot of work with your calculations.

\section{Jewel}

Out of a job... that's what it sounds like to me, and Kevin and I just can't have that! We are barely making ends meet as it is. Furthermore, if we drop BCBS patients and cut our volume in half, your administrative assistance to Aaron and Healthy Sleep will decrease in proportion. Amelia, I'm sorry, but it's a bad idea.

\section{Jill}

Amelia, it's just not financially feasible to drop BCBS! I realize it will take more work on your part to follow through with billing, as you will have ten monthly payments to track rather than one, but I know you'll find a way to keep up. Without BCBS, it's inevitable that you will get cut back to part-time. I say Healthy Sleep continues servicing BCBS patients, and you'll figure it out. Amelia, you may just need to take fewer off-site lunch breaks.

\section{Amelia}

That's quite enough, Jill! I truly doubt Aaron would schedule me part-time, even if we ended our relationship with $B C B S$, especially with all the marketing I've been planning to implement! The respiratory therapist and sleep technician hours are what will be cut, and now that I think of it, this will make a significant positive impact on the wages paid because it takes an average of two hours per set-up. This will save Healthy Sleep even more money if we have fewer overall respiratory therapist and sleep technician hours to pay. 


\section{Jackie}

Amelia, let's not get ahead of ourselves. We will most definitely stay busy enough with your marketing and our current patient base. There is no need to cut our hours. Let's just focus on what you need to do to keep things moving smoothly.

\section{Wendy}

Wait a minute! This sounds like my hours may get cut. I can't have that! I am already part time.

\section{Jewel}

It sounds like everyone's hours will have to get cut!

\section{Aaron}

Ladies, have you forgotten, I'm still here? Please, let's not get hostile. I just wanted your opinions on the matter. I am just not sure what to do at this moment, but I will get this figured out.

\section{Jill}

My opinion, Aaron... Well, I just couldn't disagree more. While I haven't crunched the numbers, I know we make more money from PAP patients than just the initial PAP equipment set-up alone. The majority of these patients also purchase supplies to the extent of $\$ 500$ to $\$ 1,500$ per patient per calendar year. This equates to a significant amount as we currently have an average of 20 new patients per month who participate with BCBS and have for the past year. That's not only a new set-up, but also supply purchases for years to come. This will add up! Aaron, you need to think through this carefully. (Refer to Table 2 for a more complete income summary.)

Table 2: Healthy Sleep Income Statement

\begin{tabular}{|l|r|c|}
\hline \multicolumn{1}{|c|}{$\begin{array}{c}\text { Healthy Sleep Supplies and Equipment, LLC } \\
\text { Income Statement } \\
\text { For the Year Ended December 31, 2012 }\end{array}$} & \multicolumn{1}{|c|}{$\mathbf{\$ 1 , 5 6 0 , 0 0 0}$} \\
\hline Revenue & $\$ 795,600$ & $\mathbf{7 6 4 , 4 0 0}$ \\
\hline Cost of Goods Sold & & \\
\hline Gross Profit & & \\
\hline Operating Expenses: & $\$ 86,000$ & \\
\hline Management Payroll & $\$ 102,000$ & \\
\hline Administrative Payroll & $\$ 110,000$ & \\
\hline Clinical Payroll & $\$ 55,000$ & \\
\hline Property Expenses & $\$ 9,500$ & \\
\hline Accounting/Professional Services & $\$ 6,800$ & \\
\hline Depreciation & $\$ 4,200$ & \\
\hline Telephone & $\$ 14,000$ & \\
\hline Technology & $\$ 16,000$ & \\
\hline Advertising/Promotion & $\$ 15,600$ & \\
\hline Office Supplies & $\$ 4,300$ & \\
\hline Bank/Credit Card Fees & $\$ 29,000$ & \\
\hline Postage/Delivery & $\$ 11,000$ & \\
\hline Insurance & & \\
\hline Total Expenses & $\mathbf{4 6 3 , 4 0 0}$ \\
\hline Pretax Income & $\mathbf{3 0 1 , 0 0 0}$ \\
\hline
\end{tabular}




\section{Jewel}

Yes, supply sales are where we need to maintain our focus. I'm currently at 50 to 60 supply orders per week! We need to focus on how we can increase these orders and generate greater revenues. Kevin and I just keep having more and more bills, and we have been thinking about getting... (Jewel abruptly stops talking).

\section{Aaron}

Okay, I think that's enough. Let's get ready for the day. Our first patient should be arriving within the next half hour. I have a lot to think about here, and I need to review this issue further with Amelia.

\section{Jackie}

Yes, we just need to have a little more faith!

(Everyone but Aaron and Amelia are exiting the conference room.)

\section{Aaron}

Jill, could you please close the door on your way out?

(The conference door slams shut.)

\section{Aaron}

(Sigh...) Alright, Amelia, I heard what you said in the meeting, but I just don't want to waste all my hard work this past year maintaining PAP sales and all. This hasn't been easy for us! I know Jason is always harping on me about cash flow, and I think he would be unhappy with having to invest more money into the company because of BCBS's reimbursement policy change. I just don't know what to do.

\section{Amelia}

Aaron, there are a lot of things you just don't see here. We could save \$30/hour if we decreased the sleep technician and respiratory therapist hours. Plus, there's the \$20/hour in administrative assistance for insurance verification. I think the cost savings will, by far, outweigh the benefits from the continued BCBS business. And, by the way, I don't think you need to involve your brother here, either. He has entrusted you with running this business, and you have all of the education and experience to do this well.

\section{Aaron}

I'm not so sure about that, Amelia. Jill and Jewel made a few good suggestions. I'm just not sure of what I should do here. Perhaps I should chat with Jason.

Also, Jill made a great point regarding the supply sales associated with the majority of PAP set-ups. I think we could pull it off. I just can't support my intuition on paper. I know Jason will request justification for why we decide to maintain or drop our BCBS patients. He's going to wonder how we came to our final decision. How can we afford to service BCBS patients, especially if he lands the state employee union contract?

\section{Amelia}

Really? You're going to take Jill's side on this decision? Unbelievable! You know she wants your job. She is just trying to get you to fail.

You know, Aaron, you should really be around here more often. I noticed you were irritated with Jackie arriving a few minutes late this morning, but the truth is, this is the earliest she's arrived to work in the past month. Quite honestly, no one's ever on time. 
And all Wendy cares about is saving the planet. She does not care about this business - just feed her a paycheck and let her run her cat rescue business during business hours; that's all she cares about.

There are a lot of other things you just don't see here.

We cannot continue working with BCBS patients; it's just not profitable.

We'll never make it through the first year. You and I can operate the rest of the business very profitably...just give it a chance.

(Amelia exits the conference room. Aaron sits with his head in his hands, wondering what he should do next.)

\section{REQUIREMENTS}

Given the dynamics of Healthy Sleep's cash flow, Aaron has hired you to assist him in analyzing the revised BCBS reimbursement terms and whether or not the DME should continue working with BCBS patients. Specific questions you should address include:

1. What is the incremental impact on Healthy Sleep's annual machine set-up cash flows from the revised BCBS reimbursement terms versus the status quo terms? In year \#1? In year \#2? Assume no growth in BCBS set-ups for this question; that is, Healthy Sleep will continue to set up 20 new BCBS patients each month.

2. Will the BCBS net cash flows become positive under the revised terms and conditions? If so, when?

3. Jason Pieper believes Healthy Sleep's BCBS set-up patient base will likely experience growth from the state union workers contract. His best estimate is that Healthy Sleep will sell incrementally an additional CPAP machine per month over a 12-month period, beginning with 20 machines sold during the upcoming month (and 21 machines in month \#2, and 22 machines in month \#3, and so on). Under this growth scenario, when will net cash flows from BCBS set-ups become positive? What is the maximum incremental working capital investment that Jason will need to finance personally from the new BCBS machine reimbursement terms under the no-growth and growth scenarios?

4. What is the impact on Healthy Sleep's annual financial performance if it decides to decline BCBS patients?

5. Should Healthy Sleep continue working with BCBS assuming no change in CPAP set-up volume?

\section{AUTHOR INFORMATION}

Timothy Moffit is Chair and Associate Professor of Economics and Business at Kalamazoo College, Kalamazoo Michigan. His teaching, research, and consulting interests include valuation, innovation, and entrepreneurship. E-mail: timothy.moffit@kzoo.edu (Corresponding author)

Michelle Gigowski is a graduate of Kalamazoo College with majors in biology and business. She currently writes and consults in health care administration, commercial real estate, and valuation practices. E-mail: michelle.r.gigowski@gmail.com

\section{TEACHING NOTE}

Faculty desiring a comprehensive teaching note should contact Timothy Moffit at timothy.moffit@kzoo.edu 


\section{NOTES}

